\title{
Challenging situations in cholecystectomy and strategies to overcome them
}

\author{
Reinhold Függer (D)
}

Received: 9 September 2020 / Accepted: 27 November 2020 / Published online: 8 January 2021

(C) The Author(s) 2021

\begin{abstract}
Summary
Background Cholecystectomy may be difficult and hazardous, causing major morbidity and mortality. This review aims to identify situations increasing the probability of difficult gallbladders and present today's best practice to overcome them.

Methods Review of the literature and expert comment. Results One in six gallbladders is expected to be a difficult cholecystectomy. The majority can be predicted by patient history, clinical symptoms, and preexisting comorbidities. Acute cholecystitis, mild biliary pancreatitis, prior endoscopic sphincterotomy, and liver cirrhosis are the predominant underlying diseases. Early or delayed cholecystectomy, percutaneous cholecystostomy, and pure conservative treatment are evidence-based options. Early laparoscopic cholecystectomy is of advantage in patients fit for surgery, with subtotal cholecystectomy or conversion to open surgery as bail-out strategies. The choice of the procedure depends on the experience of the surgeon.

Conclusion Clinical decisions should follow a pathway based on patients' risk, favoring laparoscopic cholecystectomy whenever possible. The implementation of an institutional pathway to deal with difficult gallbladders is recommended.
\end{abstract}

Keywords Difficult gallbladder · Acute cholecystitis · Surgical bail-out strategies · Subtotal cholecystectomy $\cdot$ Percutaneous cholecystostomy

Prim. Univ. Prof. Dr. R. Függer ( $ه)$

Dept of General, Visceral, Thoracic, Vascular and

Transplantation Surgery, Ordensklinikum, Linz, Austria

Johannes Kepler University, Linz, Austria

reinhold.fuegger@ordensklinikum.at
Laparoscopic cholecystectomy is the gold standard in the treatment of symptomatic cholecystolithiasis. It is one of the most frequently performed procedures in visceral surgery and a benchmark in teaching young surgeons at the beginning of their residency. In the predominant majority, cholecystectomy is a straightforward procedure and the classic model of laparoscopic surgery with low morbidity, short hospitalization, and quick reconvalescence. However, in distinct patients, cholecystectomy represents a life-threatening operation, sometimes forcing experienced surgeons to meet their technical limits. Perioperative mortality for a difficult gallbladder is as high as $11.5 \%$ for open and $2.9 \%$ for laparoscopic cholecystectomy $[1,2]$. Although the problem of the difficult gallbladder is well known in surgical practice and addressed in the literature, the term is not clearly defined and reports lack comparability due to their retrospective design, imprecise or missing definitions, differing patient populations, and individual therapeutic approaches.

This review aims to sum up what is generally understood under the term "difficult gallbladder" and addresses early preoperative recognition, the indication for operation or therapeutic alternatives, surgical techniques, and bail-out strategies to overcome intraoperative problems.

\section{What is a difficult gallbladder?}

Mostly, cholecystectomy is an uncomplicated routine laparoscopic surgery for cholelithiasis. The term "difficult gallbladder" indicates that the procedure may be challenging and hazardous. However, there is no clear definition of what is meant by a difficult gallbladder. In most articles, acute or chronic inflammation due to cholecystitis are cited as a source of surgical problems, but other conditions like pre- 
Fig. 1 Therapeutic options in a suspected difficult gallbladder. CHE cholecystectomy

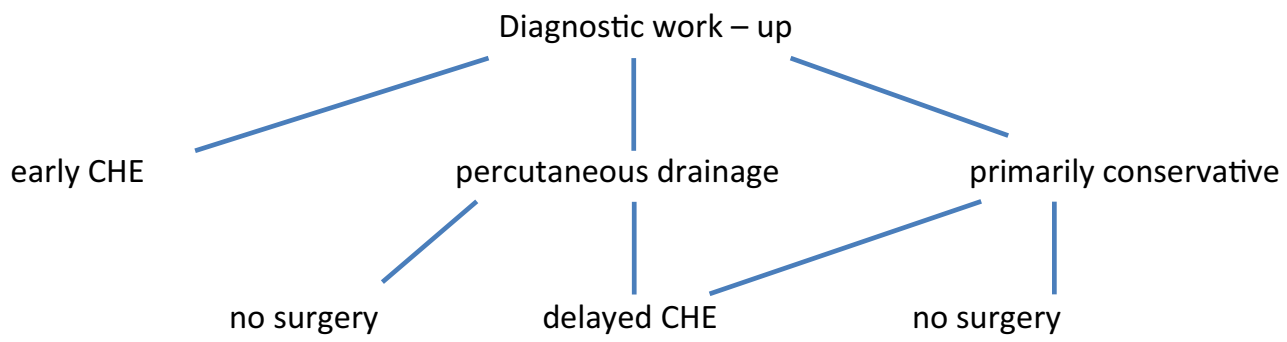

vious cholecystostomy, liver cirrhosis, coagulation therapy or disorders, and previous upper abdominal surgery are quoted elsewhere [2, 3]. More generally, the term difficult gallbladder describes a cholecystectomy which is expected to be more difficult than a routine cholecystectomy. Although the incidence of difficult gallbladders varies among series, it may be estimated that one in six gallbladders is "difficult" [4].

\section{Identification of patients}

A challenging cholecystectomy may be predicted in most patients by exploring their medical history. Thus, the evaluation of biliary symptoms and anamnesis, comorbidities, and current medication are crucial. Acute cholecystitis, biliary pancreatitis, prior endoscopic sphincterotomy for clearance of bile duct stones, liver cirrhosis, anticoagulation therapy, morbid obesity, or prior major open surgery of the upper abdomen are strong indicators that cholecystectomy may become difficult. Rarely, problems may be recognized only intraoperatively for several reasons. Examples could be a shrunk gallbladder after chronic cholecystitis, local situations with unclear anatomy in Calot's triangle, or undiagnosed liver cirrhosis.

Generally, the preoperative diagnostic workup is not different from routine cholecystectomy with physical examination of the abdomen, laboratory tests, and ultrasound of the upper abdomen. If indicated, CT, MR including MRCP, endoscopic ultrasound, and ERCP complete the initial examination.

\section{Indication for surgery}

A correct indication is a cornerstone in surgery. This is especially important if a difficult cholecystectomy is predictable. In concrete terms, the indication for cholecystectomy has to be critically challenged on an individual basis if risk factors are identified. Items to judge are the urgency of cholecystectomy and possibilities to decrease the risk and optimize the patient. As a result, cholecystectomy may be scheduled urgently, as a delayed operation, or even abandoned with conservative treatment initiated. Another important factor to consider are potential alternatives to surgery that could be provided. Especially percutaneous drainage of the gallbladder may be considered for selected patients. Last but not least, in case of an urgent cholecystectomy, the surgeon is asked to choose laparoscopic or primarily open cholecystectomy and to be prepared for bail-out strategies. An overview of decisions to be made is provided in Fig. 1.

\section{Clinical examples for difficult cholecystectomies}

\section{Acute cholecystitis}

There was a long-lasting controversy in surgery whether early or delayed cholecystectomy should be the preferred strategy in patients with acute cholecystitis. This discussion did not change with the introduction of laparoscopic cholecystectomy. Series of the early period of laparoscopic cholecystectomy described an advantage with respect to postoperative pain and length of stay for early cholecystectomy at arguable conversion rates [5]. Today, the debate has subsided to patients with specific risk factors. There is high evidence that early cholecystectomy is the superior surgical strategy in patients with acute cholecystitis [6]. In a randomized multicenter trial from Germany, early laparoscopic cholecystectomy was associated with less morbidity (11.8 vs. $34.4 \%$, $p 0.01$ ), shorter length of stay (5.4 vs. 10 days, $p 0.01$ ), and fewer costs for hospitalization (2919 vs. $4262 €$, $p$ 0.01). This study did not find a significant difference in conversion to open cholecystectomy (9.9 vs. $11.9 \%$ ) [7].

Mostly, early cholecystectomy is defined as cholecystectomy within $72 \mathrm{~h}$ from onset, which is the recommendation of the Tokyo guidelines [8]. However, it may be difficult to determine precisely how many hours from onset have passed. So other definitions of early cholecystectomy used in trials encompass $24 \mathrm{~h}$ from admission to 1 week since onset. In contrast, delayed was generally defined as cholecystectomy after 6 weeks. Last amended in 2018, the Tokyo guidelines introduced a severity assessment of acute cholecystectomy. According to the local and systemic status of inflammation and the presence of organ dysfunction, three grades of acute cholecystitis are discriminated (Table 1). Based on this grading system, therapeutic recommendations were published and reevaluated regularly $[9,10]$. While the Tokyo guidelines helped to establish the role of early laparoscopic cholecystectomy in grade I, the therapeutic strategy remained less clear for grades II and III. Loozen et al. demonstrated similar results of emergency cholecystectomy with respect to conversion rate (6 vs. $6 \%$ ), complica- 
Table 1 Severity assessment of acute cholecystitis according to the Tokyo guidelines

\begin{tabular}{|c|c|}
\hline $\begin{array}{l}\text { Grade I } \\
\text { (mild) }\end{array}$ & $\begin{array}{l}\text { Does not meet the criteria of grade II or grade III acute } \\
\text { cholecystitis. Can also be defined as acute cholecystitis in } \\
\text { a healthy patient with no organ dysfunction and mild } \\
\text { inflammatory changes in the gallbladder }\end{array}$ \\
\hline \multirow{5}{*}{$\begin{array}{l}\text { Grade II } \\
\text { (moderate) }\end{array}$} & Associated with any one of the following conditions: \\
\hline & 1. Elevated white blood cell count $\left(18,000 / \mathrm{mm}^{3}\right)$ \\
\hline & 2. Palpable tender mass in the right upper abdominal quadrant \\
\hline & 3. Duration of complaints $72 \mathrm{~h}$ \\
\hline & $\begin{array}{l}\text { 4. Marked local inflammation (gangrenous cholecystitis, } \\
\text { pericholecystic abscess, hepatic abscess, biliary peritonitis, } \\
\text { emphysematous cholecystitis) }\end{array}$ \\
\hline \multirow[t]{7}{*}{$\begin{array}{l}\text { Grade III } \\
\text { (severe) }\end{array}$} & $\begin{array}{l}\text { Associated with dysfunction of any of the following organs/ } \\
\text { systems: }\end{array}$ \\
\hline & $\begin{array}{l}\text { 1. Cardiovascular dysfunction (hypotension requiring treatment } \\
\text { with dopamine } 5 \mu \mathrm{g} / \mathrm{kg} \text { per min or any dose of norepinephrine) }\end{array}$ \\
\hline & 2. Neurological dysfunction (decreased level of consciousness) \\
\hline & 3. Respiratory dysfunction $\left(\mathrm{PaO}_{2} \mathrm{FiO}_{2}\right.$ ratio 300$)$ \\
\hline & 4. Renal dysfunction (oliguria, creatinine $2.0 \mathrm{mg} / \mathrm{dl}$ ) \\
\hline & 5. Hepatic dysfunction (PT-INR 1.5) \\
\hline & 6. Hematological dysfunction (platelet count $100,000 / \mathrm{mm}^{3}$ ) \\
\hline
\end{tabular}

tion rate ( 7 vs. $9 \%$ ), mortality ( 1 vs. $1 \%$ ), and length of stay ( 4 vs. 4 days) in patients with grade I and grade II acute cholecystitis [11]. Indeed, the Tokyo guidelines' update of 2018 recommends early laparoscopic cholecystectomy in moderate acute cholecystitis (grade II) for patients with limited risk factors (Charlson comorbidity index $\leq 5$ or ASA $\leq 2$ ) in advanced centers by experienced laparoscopic surgeons. Moreover, for severe acute cholecystitis (grade III), early laparoscopic cholecystectomy is an option if the patient is estimated to be fit for surgery and a setting of intensive care management and extensive laparoscopic experience is provided. Clearly, the Tokyo guidelines' therapeutic recommendations for moderate and severe acute cholecystitis indicate the need for an institutionalized concept for surgical departments, depending on the hospital setting and surgical experience. Patients who are decided to be unfit for early cholecystectomy due to high individual risk factors need urgent gallbladder drainage for source control. In practice, these interventions are provided in centers with high institutional experience and a continuous case load. Aside from guideline recommendations, it is clearly proven that time matters in surgical therapy of acute cholecystitis. An analysis of the Swedish GallRiks Registry demonstrates a correlation of the rate of bile duct injuries with acute cholecystitis. Overall, the incidence in acute cholecystitis was 0.43 vs. $0.28 \%$ in patients without cholecystitis. The rate for patients with acute cholecystitis increased markedly from $0.17 \%$ in cholecystectomies on the day of admission to $0.67 \%$ for 3 days after admission to $0.93 \%$ for 5 days and longer. Interestingly, there was also a significantly increased 30- and 90-day mortality when operations were performed after the fourth day of admission [12].

\section{Biliary pancreatitis}

The timing of laparoscopic cholecystectomy in patients with mild biliary pancreatitis is another item of debate in clinical routine. Mostly, patients were discharged following the episode of biliary pancreatitis and scheduled for an interval cholecystectomy. The background for this strategy was an estimated higher risk for cholecystectomy-related complications in early surgery. However, the PONCHO trial, a multicenter randomized controlled trial from the Netherlands, could prove that cholecystectomy during the same hospital admission is superior to interval cholecystectomy regarding the rate of recurrent gallstonerelated complications without increasing the surgical risk [13]. Patients were randomized 5 days after admission for mild biliary pancreatitis and operated on day one in the same admission or day 27 in the interval group. The primary endpoint of readmission for gallstone-related complications or mortality was significantly lower when cholecystectomy was performed in the same admission (5 vs. 17\%, $p$ 0.002). Nevertheless, the fear of a difficult cholecystectomy with increased complication rates may hinder consequent implementation of a same admission cholecystectomy. The Dutch Pancreatitis Study Group analyzed the rate of difficult cholecystectomies in their PONCHO trial [14]. They defined difficult cholecystectomy as one or more of the three factors, enhanced score of difficulty to perform laparoscopic cholecystectomy, operating time $75 \mathrm{~min}$, and conversion or subtotal cholecystectomy. Overall, $33 \%$ of patients fulfilled the criteria of difficult cholecystectomy, $26 \%$ in the same admission and $39 \%$ in the interval group $(p=0.037)$. Male sex, prior sphincterotomy, and delaying cholecystectomy for at least 14 days were identified to increase the probability of a difficult cholecystectomy.

\section{Laparoscopic cholecystectomy for cholecystocholedocholithiasis}

There exist several strategies to treat patients with cholecystolithiasis and bile duct stones. Amongst these concepts, therapeutic splitting with prior clearance of the bile ducts by endoscopic sphincterotomy and subsequent laparoscopic cholecystectomy is most commonly applied. In a large populationbased analysis in British Columbia, in $44.4 \%$ timing followed an early cholecystectomy strategy within 2 days after sphincterotomy and in $55.6 \%$ a delayed cholecystectomy [15]. This survey reflects clinical practice to some extent, with a wide variation in scheduling laparoscopic cholecystectomy. As in mild biliary pancreatitis, early laparoscopic cholecystectomy may be seen as a more difficult operation with 
increased complication rates. Furthermore, increased serum amylase as an indicator of a mild post-sphincterotomy pancreatitis may delay surgery. Indeed, several reports found a higher conversion rate compared to standard laparoscopic cholecystectomy [16, 17]. In contrast, overall conversion rates for laparoscopic cholecystitis after endoscopic sphincterotomy are most often lower (4-23\% for early vs. $8-55 \%$ for delayed) and recurrent biliary events less frequent (2-10\% early vs. $24-47 \%$ delayed) for early cholecystectomy [18-20]. In an RCT comparing laparoscopic cholecystectomy within 3 days and 6-8 weeks after endoscopic sphincterotomy, no significant difference in conversion rates (4.3 early vs. $8.7 \%$ delayed), operating times, or length of stay was detected. But there was a marked difference in biliary events in the waiting period, with $2 \%$ in the early and $36.2 \%$ in the delayed group. Consequently, the ESGE guidelines recommend laparoscopic cholecystectomy within 2 weeks from endoscopic sphincterotomy. This is quoted as a strong recommendation with moderatequality evidence [21].

\section{Cirrhosis}

According to the above-cited Swedish Registry for Gallstone Surgery (GallRiks), only $0.12 \%$ of cholecystectomies are performed in patients with liver cirrhosis [22]. Compared with noncirrhotic patients, the incidence of postoperative complications was higher ( 16.9 vs. $9.2 \%, p$ 0.05). However, the conclusion of the registry is that cholecystectomy should not be delayed in patients with an adequate indication. One of the largest series of laparoscopic cholecystectomies in cirrhotic patients was recently published by Gad et al. [23]. In a cohort of 213 cirrhotic patients operated between 2011 and 2019, 30-day morbidity and mortality were 22.1 and $2.3 \%$. Nevertheless, Child-Pugh class, MELD score, and acuity increase perioperative mortality significantly. In a survey of herniorrhaphies and cholecystectomies in cirrhotic patients, mortality was zero, 8.8, and $10.7 \%$ for Child A, B, and C, respectively [24]. Emergency surgery raised mortality to $20 \%$.

\section{Anticoagulation}

The number of patients with antithrombotic therapy undergoing surgery is increasing steadily. Preoperatively, this raises the question of whether this therapy should be maintained, adopted, or withdrawn to keep perioperative hemorrhagic complications low. Especially in acute surgery, this problem needs urgent consideration. In general, the incidence of postoperative bleeding complications is determined by the intensity of antithrombotic therapy. In a review of 1075 patients undergoing abdominal laparoscopic surgery, no increase in hemorrhagic complications was found in patients with continued antiplatelet therapy compared to patients with preoperatively suspended or without therapy [25]. A recently published analysis of the effect of antithrombotic therapy in emergency cholecystectomy by the same authors underlines the need of a differentiated approach. Multiple antiplatelet therapy, anticoagulation, male sex, limited performance status, and grade II and III acute cholecystitis were independent risk factors for increased intraoperative blood loss and postoperative bleeding. Single antiplatelet therapy was not associated with hemorrhagic complications [26]. An individual approach balancing each patient's risk of thrombotic or bleeding complications is therefore crucial.

\section{Morbid obesity}

Morbid obesity seems to be a clear risk factor for a difficult cholecystectomy. Indeed, a recent review on risk factors for conversion of laparoscopic to open cholecystectomy found that 8 of 19 studies analyzing BMI found that conversion was significantly higher in patients with a BMI above $30 \mathrm{~kg} / \mathrm{m}^{2}$ [27]. Going into detail, there may be a variety of reasons why the conversion rate is higher according to this review. All of them are technical issues, like the length and positioning of trocars, fatty infiltration of Calot's triangle, and unclear anatomy. However, it remains unclear whether obesity is really a reason for a difficult cholecystectomy. A retrospective comparison of day-case cholecystectomy in patients with a BMI $30 \mathrm{~kg} / \mathrm{m}^{2}$ and obese patients indicated by a BMI above $30 \mathrm{~kg} / \mathrm{m}^{2}$ revealed a technically more demanding procedure in the obese group. However, there were no strong indicators for a major impact of obesity. Conversion rates, overall complications, and the incidence of readmission were not markedly different [28].

\section{Surgical techniques for a difficult cholecystectomy}

Once access to the abdomen has been successful and pneumoperitoneum established, attention concentrates on Calot's triangle. Inflammation may hinder anatomical dissection and correct identification of the cystic duct, bile duct, and hepatic and cystic arteries. Thus, providing an appropriate procedure for cholelithiasis and avoiding iatrogenic damage represent the crucial tasks for surgeons. Surgical strategies to overcome such a hazardous situs at Calot's triangle include the effort to continue laparoscopically and convert to open cholecystectomy if necessary, or to aim for laparoscopic subtotal cholecystectomy to avoid conversion. If these maneuvers cannot clear the situation, a change from open total to subtotal cholecystectomy and from laparoscopic subtotal to open subtotal cholecystectomy complete the possibilities to bail out.

Leaving a part of the gallbladder in situ as an exit strategy from surgical troubles is not new. In the lit- 
erature, the first publication is credited to Floreken in 1912 [29].

Recently, an increase in laparoscopic and open subtotal cholecystectomies was reported in an analysis of 290,855 patients undergoing cholecystectomy for acute cholecystitis in the US from 2003 to 2014 [30]. The rate of open and laparoscopic subtotal cholecystectomy increased from 0.10 to $0.52 \%$ and from 0.12 to $0.28 \%$, respectively. In the same period, conversion from laparoscopic to open total cholecystectomy dropped from 10.5 to $7.6 \%$, thus indicating that laparoscopic subtotal cholecystectomy is an effective bail-out measure and reduces conversion. It may also have the potential to reduce the rate of bile duct injuries. Sabour et al. report that $0.67 \%$ of patients with converted open total and subtotal cholecystectomy had to undergo bile duct repair, compared to none in the laparoscopic subtotal group. Similar findings have been published in single-center series. Purzner et al. report in a comparative study on four bile duct injuries in 105 patients undergoing laparoscopic cholecystectomy for severe cholecystitis, while there were none in 45 laparoscopic subtotal cholecystectomies [31]. Lacking comparability of patient cohorts prevents higher evidence regarding to what extent laparoscopic subtotal cholecystectomy is really able to decrease bile duct injury rates. According to a meta-analysis, subtotal cholecystectomies are performed laparoscopically in $72.9 \%$, open in $19 \%$, and converted from laparoscopic to open in $8 \%$, with the predominant indication of severe cholecystitis followed by cirrhosis and empyema or gallbladder perforation in $72.1,18.2$, and $6.1 \%$, respectively [32].

Laparoscopic subtotal cholecystectomy with a fenestrating and a reconstituting subtype as a bail-out strategy for difficult gallbladders was published by Strasberg [3]. However, there remain some critical issues for laparoscopic subtotal cholecystectomy: conversion rates of $12.7 \%$ and $43.8 \%$, bile leaks in $17.6 \%$ and $8.2 \%$, reinterventions in $32.4 \%$ and $26 \%$, and the need for completion cholecystectomy in $8.9 \%$ and $17.8 \%$ for fenestrating and reconstituting laparoscopic subtotal cholecystectomy, respectively [33]. Despite these drawbacks, the profound meta-analysis of Elshaer $\mathrm{M}$ et al. underlines the importance of subtotal cholecystectomy in the treatment of difficult gallbladders. Rates of 30-day mortality $(0.4 \%)$, bile duct injury $(0.08 \%)$, postoperative hemorrhage $(0.3 \%)$, and reoperations $(1.8 \%)$ are favorable results. Again, the most striking complication was bile leaks in $18 \%$ [32].

Alternative data from Ashfaq et al. for laparoscopic total cholecystectomy in difficult gallbladders reveal a conversion rate of $19.9 \%$, caused by severe inflammation, difficult anatomy, or bleeding. There was no bile duct injury in their cohort of 351 patients. Bleeding (3.9 vs. $7.1 \%$ ), bile leak (1.8 vs. $4.3 \%$ ), surgical site infection ( 2.8 vs. $8.6 \%$ ), and mortality ( 0.4 vs. $2.9 \%$ ) were higher but not significantly elevated com- paring the laparoscopically completed and the open converted group [2].

In this debate surrounding conversion and the extent of cholecystectomy, technical items are to be considered too. While surgical dissection of Calot's triangle is often difficult and hazardous, a fundus-first technique may facilitate completion of total laparoscopic cholecystectomy.

Percutaneous cholecystostomy is a possible alternative to urgent cholecystectomy. However, its application varies considerably. In a nationwide comparison of percutaneous cholecystostomy and emergency cholecystectomy for acute calculous cholecystitis, data of 248,229 patients with acute cholecystitis were analyzed [34]. There was a lower rate of complications (OR 0.3, $p$ 0.001) but higher odds for mortality (OR 5.2, $p$ 0.001), increased costs, and prolonged hospitalization in patients undergoing percutaneous cholecystostomy. Patient groups were not comparable, with higher age and more comorbidities in those undergoing cholecystostomy. Recently, similar results were reported in a comparison of 11,184 PC and 225,558 cholecystectomies from Taiwan [35]. Mortality was increased in the percutaneous cholecystostomy group from minimum of 1.45-fold to a maximum of 34.22 -fold in diverse subgroups. The difference was smaller in aged patients and for severe cholecystitis. Furthermore, recurrent cholecystitis, readmission because of biliary complications, and $36 \%$ in need of subsequent cholecystectomy challenge the indication for percutaneous cholecystostomy and favor emergency cholecystectomy. Problems of interval cholecystectomy after percutaneous cholecystostomy are addressed in an analysis by Ackerman et al. [36]. Compared with patients undergoing urgent cholecystectomy for acute cholecystitis, patients with interval cholecystectomy following percutaneous cholecystostomy had longer operation times (120.7 vs. $92.5 \mathrm{~min}, p 0.0001)$, increased conversion rates $(26.6$ vs $12.8 \%, p 0.001$ ), and increased bowel injury (6.2 vs. $0.4 \%, p 0.001$ ). As a sign of higher comorbidity, they also were older, had a higher ASA class and, higher 1 -year mortality (15.3 vs. $0.4 \%, p 0.01$ ). Percutaneous cholecystectomy has a restricted role in severe cholecystitis and patients not fit for surgery, but awareness should be presumed that not all biliary problems are solved by PC and interval cholecystectomy remains demanding.

\section{Clinical pathways}

At the beginning of decision-making the question should be whether the gallbladder, in most patients acute cholecystitis, is the leading source of current disease. The severity of acute cholecystitis, time since onset of symptoms, and patients' comorbidities have to be determined and possibilities for optimizing the patients' health status checked. Based on this clinical information and additional workup, the decision has 
Fig. 2 Bail-out strategies. CHE cholecystectomy

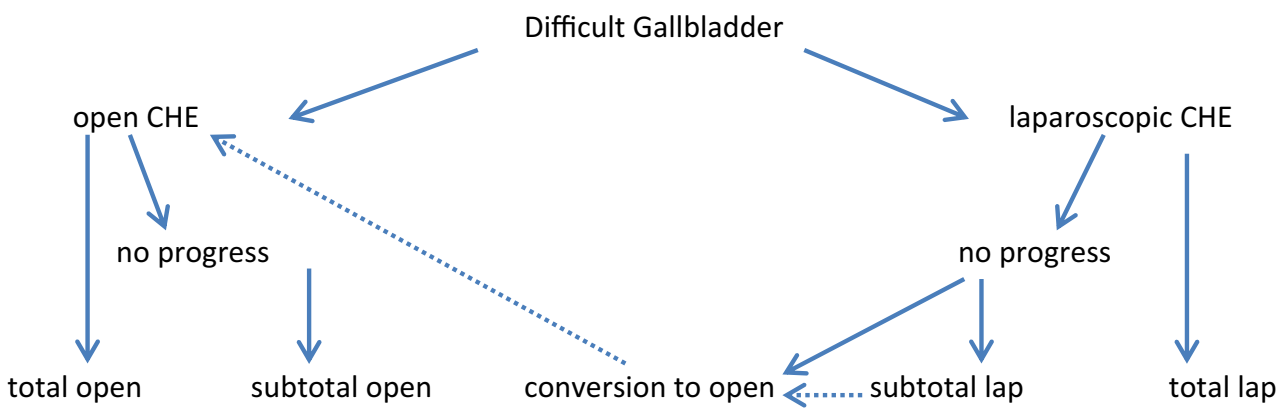

to be taken for early operation or conservative therapy, potentially with additional percutaneous gallbladder drainage. Especially in grade II and III acute cholecystitis, this will be an individual decision. An argument for early cholecystectomy is the potential to eliminate the source in one single step, thus keeping the course of the disease short. In contrast, perioperative complications and underestimated comorbidities may hinder postoperative progress. The opposite approach is to keep the intervention at the beginning as minimally traumatic as possible by percutaneous drainage or even pure conservative therapy and postpone more traumatic surgery until the patient is stable. Missing source control with recurrent biliary problems and prolonged hospitalization with an increased risk for secondary medical complications are the drawbacks of this strategy. As there is no approach without cons, an individual patient-centered decision is required. Recommendations from guidelines are of limited value. Especially for moderate acute cholecystitis, the Tokyo guidelines give percutaneous gallbladder drainage a prominent importance that is not consistently confirmed in the literature. There is considerable evidence that early laparoscopic cholecystectomy in moderate acute cholecystitis is feasible with low morbidity and mortality [11]. Provided the surgeon has advanced laparoscopic skills, this also applies for selected patients with severe acute cholecystitis.

There is no high-quality evidence-based recommendation regarding which surgical technique should be chosen. If a cholecystectomy is performed, whether total laparoscopic or primarily open and which bailout strategies are applied depends on the experience of the surgeon and clinical judgement. The former role of primarily open cholecystectomy as the manifest alternative to laparoscopic cholecystectomy in difficult gallbladders has to be challenged, due to diminished surgical experience with the open procedure [37]. Finally, an individual surgical approach with close workup of complications in interdisciplinary morbidity and mortality rounds is reasonable. Fig. 2 represents a personal strategy for the choice of the type of cholecystectomy and possibilities to bail out.

\section{Conclusion}

There is no single absolutely verified pathway for how to deal with challenging situations in cholecystectomy. This is due to multiple diseases and factors causing such problems and individual patient risks and demands. Considering these limitations, there is evidence that early cholecystectomy has advantages over delayed surgery. Especially for acute moderate cholecystitis, mild biliary pancreatitis, and cholecystectomy following endoscopic sphincterotomy, this has been proven sufficiently, although the clinical implementation of this evidence in routine surgery needs to be optimized. Interval cholecystectomies should be avoided whenever possible because of their increased operative risks, and percutaneous cholecystostomies reserved for patients absolutely unfit for acute surgery. Bail-out strategies are determined by the experience of the surgeon and the hospital setting. Last but not least, an institutional clinical pathway on how to deal with a challenging cholecystectomy should be implemented.

Funding Open access funding provided by Johannes Kepler University Linz.

Conflict of interest R. Függer declares that he has no competing interests.

Open Access This article is licensed under a Creative Commons Attribution 4.0 International License, which permits use, sharing, adaptation, distribution and reproduction in any medium or format, as long as you give appropriate credit to the original author(s) and the source, provide a link to the Creative Commons licence, and indicate if changes were made. The images or other third party material in this article are included in the article's Creative Commons licence, unless indicated otherwise in a credit line to the material. If material is not included in the article's Creative Commons licence and your intended use is not permitted by statutory regulation or exceeds the permitted use, you will need to obtain permission directly from the copyright holder. To view a copy of this licence, visit http://creativecommons.org/licenses/by/4.0/.

\section{References}

1. Spohnholz J, Herzog T, Munding J, et al. Conversion cholecystectomy in patients with acute cholecystitis-it's not as black as it's painted! Langenbecks Arch Surg. 2016;401(4):479-88. 
2. Ashfaq A, Ahmadieh K, Shah AA, Chapital AB, Harold KL, Johnson DJ. The difficult gall bladder: outcomes following laparoscopic cholecystectomy and the need for open conversion. Am J Surg. 2016;212:1261-4.

3. Strasberg SM, Pucci MJ, Brunt LM, Deziel DJ, et al. Subtotal choleycstectomy - "Fenestrating" vs "Reconstituting" subtypes and the prevention of bile ductinjury: definition of the optimal procedure in difficult operative conditions. J Am Coll Surg. 2016;222(1):89-96.

4. Salky BA, Edye MB, et al. The difficult cholecystectomy: problems related to concomitant diseases. Semin Laparosc Surg. 1998;5(2):107-14.

5. Adamer K, Salzmann M, Imhof M, Zacherl J, Raduly F, Függer $\mathrm{R}$ et al. Postoperative benefit after laparoscopic cholecystectomy in acute cholecystitis. Zentralbl Chir. 1997;122(4):287-90.

6. Függer R, Dutta-Függer B. Chirurgische Infektionen der Gallenblase und der Gallenwege. Zentralbl Chir. 2007;132:438-41.

7. Gutt CN, Encke J, Köninger J, Harnoss JC, et al. Acute cholecystitis: early versus delayed cholecystectomy, a multicentrerandomized trial (ACDC study, NCT00447304). Ann Surg. 2013;258(3):385-93.

8. Okamoto K, Suzuki K, Takada T, et al. Tokyo Guidelines 2018: flowchart for the management of acute cholecysitits. JHepatobiliary Pancreat Sci. 2018;25:55-72.

9. Miura F, Takada T, Kawarada Y, et al. Flowcharts for the diagnosis and treatment of acute cholangitis and cholecystitis: Tokyo Guidelines. J Hepatobiliary Pancreat Surg. 2007;14:27-24.

10. Miura F, Takada T, Strasberg SM, et al. TG13 flowchart for the management of acute cholangitis and cholecystitis. JHepatobiliary Pancreat Sci. 2013;20:47-54.

11. Loozen CHS, Blessing MM, van Ramshorst B, van Santvoort HC, Boerma D. The optimal treatment of patients with mild and moderate acute cholecystitis: time for a revision of the Tokyo Guidelines. Surg Endosc. 2017;31:3858-63.

12. Blohm M, Österberg J, Sandblom G, et al. The sooner, the better? The importance of optimal timing of cholecystectomy in acute cholecystitis: data from the national Swedish registry for gallstone surgery, gallRiks. J Gastrointest Surg. 2017;21(1):33-40.

13. Da Costa DW, Bouwense SA, Schepers NJ, et al. Sameadmission versus interval cholecystectomy for mild gallstone pancreatitis (PONCHO): a multicentre randomised controlled trial. Lancet. 2015;386:1261-8.

14. Da Costa DW, Schepers NJ, Bouwense SA, et al. Predicting adifficultcholecystectomyaftermildgallstonepancreatitis. HPB. 2019;21(7):827-33.

15. MadorBD, Nathens AB, XiongW, PantonONM, HameedSM. Timing of cholecystectomy following endoscopic sphinterotomy: a population-based study. Surg Endosc. 2107;31:2977-85.

16. Reinders JSK, Goud A, Timmer R, et al. Early laparoscopic cholecystectomy improves outcomes after endoscopic sphincterotomy for choledochocystolithiasis. Gastroenterology. 2010;138(7):2315-20.

17. Sarli L, Iusco DR, Roncoroni L. Preoperative endoscopic sphincterotomy and laparoscopic cholecystectomy for the management of cholecystocholedocholithiasis: 10-year experience. World J Surg. 2003;27:180-6.

18. Boerma D, Rauws EA, Keulemans YC, et al. Wait-and-see policy or laparoscopic cholecystectomy after endoscopic sphincterotomy for bile-duct stones: a randomised trial. Lancet. 2002;360:761-5.
19. De Vries A, Donkervoort SC, van Geloven AA, et al. Conversion rate of laparoscopic cholecystectomy after endoscopic retrograde cholangiography in the treatment of choledocholithiasis: does the time interval matter? Surg Endosc. 2005;19:996-1001.

20. Schiphorst AH, Besselink MG, Boerma D, et al. Timing of cholecystectomy after endoscopic sphincterotomy for common bile duct stones. Surg Endosc. 2008;22:2046-50.

21. Manes G, Paspatis G, Aabakken L, et al. Endoscopic management of common bile duct stones: European Society of Gastrointestinal Endoscopy (ESGE) guideline. Endoscopy. 2019;51:472-91.

22. Strömberg J, Hammarqvist F, Sadr-Azodi O, Sandblom G. Cholecystectomy in patients with liver cirrhosis. Gastroenterol Res Pract. 2015. https://doi.org/10.1155/2015/ 783823

23. Gad EH, Ayoup E, Kamel Y, et al. Surgical management of laparoscopic cholecystectomy (LC) related major bile duct injuries; predictors of short-and long-term outcomes in a tertiary Egyptian center-a restrospective cohort study. Ann Med Surg. 2018;36:219-30.

24. Alsina AE, Athienitis A, Nakshabandi A, et al. Outcomes of abdominal surgeries in cirrhotic patients performed by liver transplant surgeons: are these safe? Am J Surg. 2018;216(3):518-23.

25. Fujikawa T, Tanaka A, Abe T, et al. Does antiplatelet therapy affect outcomes of patients receiving abdominal laparoscopic surgery? Lessons from more than 1,000 laparoscopic operations in a single tertiary referral hospital. JAm Coll Surg. 2013;217(6):1044-53.

26. Kawamoto Y, Fujikawa T, Sakamoto Y, et al. Effect of antithrombic therapy on bleeding complications in patients receiving emergency cholecystectomy for acute cholecystitis. JHepatobiliary Pancreat Sci. 2018;25(11):518-26.

27. Hu ASY, Menon R, Gunnarsson R, De Costa A. Risk factors for conversion of laparoscopic cholecystectomy to open surgery-A systematic literature review of 30 studies. Am J Surg. 2017;2014:920-30.

28. Floreken H. Gallenblasenregeneration mit Steinrecidive nach Cholecystectomie. Dtsch ZCir. 1912;13:604-6.

29. Gregori M, Miccini M, Biacchi D, et al. Dy case laparoscopic cholecystectomy: safety an feasibility in obese patients. Int JSurg. 2018;49:22-6.

30. Sabor AFMD, Matsushima KMD, Love BEMD, et al. Nationwide trends in the use of subtotal cholecystectomy for acute cholecystitis. Surgery. 2020;167:569-74.

31. Purzner RH, Ho KB, Al-Sukhni E, Jayaraman S. Safe laparoscopic subtotal cholecystectomy in the face of severe inflammation in the cystohepatic triangle: a retrospective review and proposed management strategy for the difficult gallbladder. Can J Surg. 2019;62(6):402-11.

32. Elshaer M, Gravante G, Thomas K, Sorge R, Al-Hamali S, Ebdewi H. Subtotal cholecystectomy for "Difficult Gallbladders". Systematic review and meeta-analysis. JAMA Surg. 2015;150(2):159-68.

33. Van Dijk AH, Donkervoort SC, Lameris W, et al. Shortand long-term outcomes after a reconstituting and fenestrating subtotal cholecystectomy. J Am Coll Surg. 2017;225(3):371-9.

34. Anderson JE, Chang DC, Talamini MA. A nationwide examination of outcomes of percutaneous cholecystostomy compared with cholecystectomy for acute cholecystitis, 1998-2010. Surg Endosc. 2013;27(9):3406-11.

35. Lu P, Chan CH, Yang NP, Chang NT, Lin KB, Lai KR. Outcome comparison between percutaneous cholecystostomy and cholecystectomy: a 10-year population-based analysis. BMCSurg. 2017;17:130. 
36. Ackerman JMD, Abegglen RMD, Scaife MMD, et al. Beware of the interval cholecystectomy. J Trauma Acute Care Surg. 2017. 83(1):55-60.

37. Ammann M, LängleF. The complicated gallbladder-is oldschool treatment an alternative? Eur Surg. 2020; https:// doi.org/10.1007/s10353-020-00653-0.

Publisher's Note Springer Nature remains neutral with regard to jurisdictional claims in published maps and institutional affiliations. 